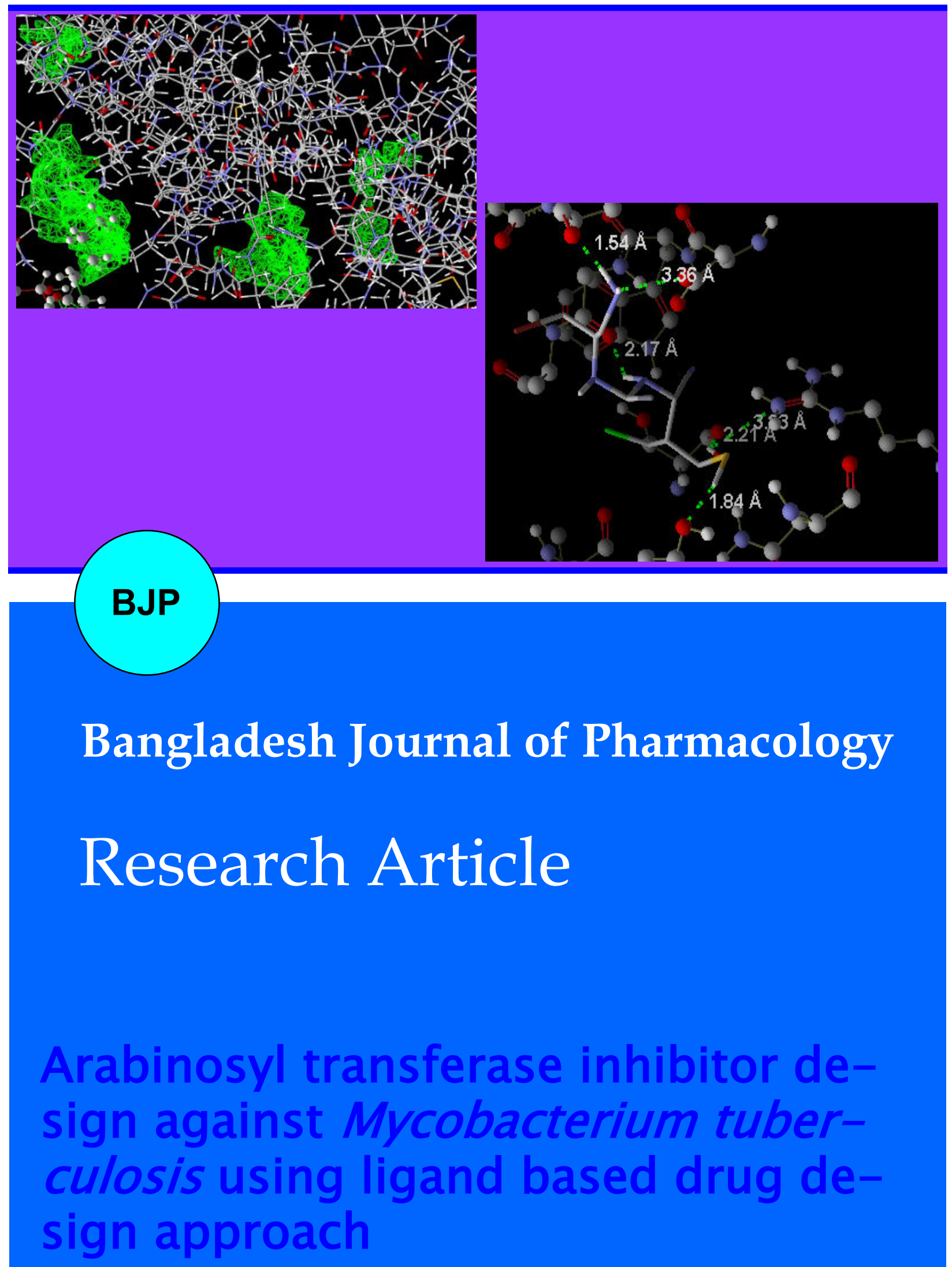




\section{Arabinosyl transferase inhibitor design against Mycobacterium tuberculosis using ligand based drug design approach}

\section{Bhaskor Kolita' ${ }^{1}$, Dhrubajyoti Gogoi ${ }^{2}$, Partha Pratim Dutta ${ }^{3}$, Manobjyoti Bordoloi ${ }^{3}$ and Rajib Lochan Bezbaruah²}

${ }^{1}$ Centre for Bioinformatics Studies, Dibrugarh University, Dibrugarh, Assam, India; ${ }^{2} D B T$-Bioinformatics Infrastructure Facility, Biotechnology Division, North East Institute of Science and Technology (Formerly Regional Research Laboratory), CSIR, Government of India, Jorhat, Assam, India; ${ }^{3}$ Natural Product Chemistry Division, North East Institute of Science and Technology (Formerly Regional Research Laboratory), CSIR, Government of India, Jorhat, Assam, India.

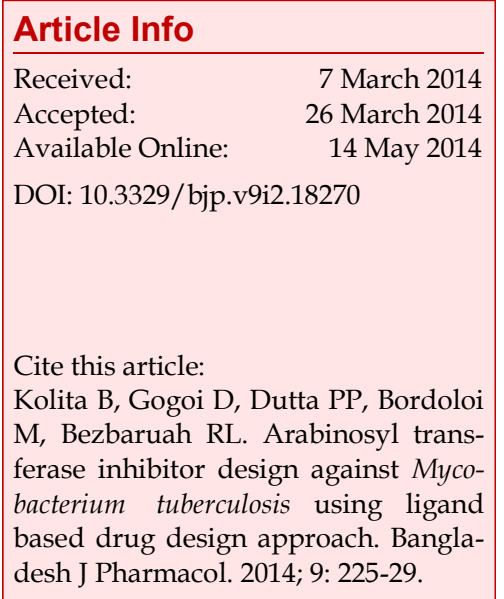

\section{Introduction}

Tuberculosis is a common as well as one of the deadly infectious diseases caused by Mycobacterium tuberculosis. It affects most of the world's population, mainly in developing countries (Harries and Dye, 2006; Lopez and Mathers, 2006) Antibiotics were prescribed but effective treatment is challenging due to the complicated structure and chemical composition of the mycobacterium cell wall. The unusual structure of the bacterial cell wall makes many antibiotics ineffective and check the entry of drugs (Jain and Mondal, 2008).

Isoniazid and ethambutol have been used for the decades as frontline drugs to inhibit $M$. tuberculosis, but the rise of multi-drug resistant and extensively drug resistant strains poses a serious threat to present treatment of tuberculosis (Burris, 2004; McIlleron et al., 2009; Zhang et al., 2014). Ethambutol inhibits the synthesis of essential components of the mycobacterial cell wall. Ethambutol targets the biosynthesis of the cell wall, inhibiting the synthesis of both arabinogalactan and lipoarabinomannan. It is assumed to act via inhibition of arabinosyl transferases (Amin et al., 2008).

An arabinosyltransferase is a transferase enzyme acting upon arabinose belongs to the family of glycosyl transferases. Ethambutol has been also reported for several toxic effects such as optic neuritis, color blindness etc (Kumar et al., 1993). Therefore, the need of new and alternative drug candidate for tuberculosis is obvious and current approaches is aim to screened lead 
molecule from chemical database using Computer aided screening methodology based of known chemical structure of ethambutol.

\section{Materials and Methods \\ Receptor and ligand retrieval and analogs design for ethambutol}

The 3-D structure of arabinosyl transferase (3PTY) was retrieved from Protein Data Bank. The structure of ethambutol was also retrieved from Drug Bank. Structural similarity, sub-structure, identity (70\%) search were performed and carried out for ethambutol like compounds using Molsoft ICM Browser 3.5-1p and ChemBioDraw Ultra 12.0 software (Gogoi et al., 2012; Lagunin et al., 2000). Compounds library were collected from ZINC Database, PubChem, Chemspider, ChemBank cheminformatics site in sdf format. Ethambutol structure based analogs were also designed manually using Chem Sketch software. Around 100,000 compounds were considered and screened for ethambutol like candidate lead compound. Open BabelGUI tool was used for chemical file conversion purposes.

\section{Ligand structure optimization and physiochemical properties calculation}

Screened lignads were optimized before docking using MM2 force field of ChemBio 3D ultra. Physiochemical properties (Hydrogen bond acceptor, hydrogen bond donor, number of rotatable bond, calculated $\log \mathrm{P}$, molecular weight, etc) were predicted and checked for non-violation of drug like and Lipinski's rules using PreADMET server.

Potential protein binding sites prediction and molecular docking study

The potential ligand binding site of arabinosyl transferase receptor was computed at MVD workspace. Volume and Surface of the binding site were computed and optimum binding site was selected to perform docking. The screened compounds were imported in the Molegro Virtual Docker workspace. The bonds flexibility of the ligands was set and the side chain flexibility of the amino acids in the binding cavity was set with a tolerance of 1.1 and strength of 0.9 for docking simulations. RMSD threshold for multiple cluster poses was set at $<2.00 \AA$. The docking algorithm was set at a maximum iteration of 1500 with a simplex evolution size of 50 and a minimum of 20 runs. Molecular docking was carried out using Molegro Virtual Docker (MVD) (Molegro APS: MVD 5.0) (Thomsen and Christensen, 2006). MVD is molecular visualization and molecular docking software which is based on a differential evolution algorithm; the solution of the algorithm takes into account the sum of the intermolecular interaction energy between the ligand and the protein and the intramolecular interaction energy of the ligand. The docking energy scoring function is based on the modified piecewise linear potential (PLP) with new hydrogen bonding and electrostatic terms included. Interaction of Ligands with recetor was studied to know the best binding orientation of receptor -ligand complex in terms of minimum energy score.

\section{ADME and toxicity prediction}

Absorption, distribution, metabolism, excretion and toxicity were studied for top ranking compounds were computed using PASS (Prediction of Activity Spectra for Substances) Inet and Pre ADMET server (Gogoi et al., 2012; Lagunin et al., 2000). PASS Inet predicts 3678 pharmacological effects, mechanisms of action, mutagenicity, carcinogenicity, teratogenicity and embryotoxicity. MDCK cell permeability, human intestinal absorption, blood-brain barrier penetration and plasma protein binding scores were studied and compared (Norinder and Bergstrom, 2006).

\section{Result and Discussion}

Herein, we have screened out 3148 compounds structurally similar with ethambutol from 11,74,583 compounds based on chemical similarity (structural) using ZINC database. We have also retrieved ethambutol like 5 compounds from Chemspider on the basic of calculated property, 10 from ChemBank on the basic of substructure and 3 from Pubchem on the basic of property. We calculated physicochemical property for 222 compounds in Molsoft ICM-Browser software and observe that most of the compounds follows Lipinski's rule of Five as presented in the Table I including few analogues of ethambutol.

The compounds with the predicted drug likeness of more than $80 \%$ with Lipinski's qualification were used to study their ADME properties. 222 compounds were checked for absorption and distribution in human body using PreADMET as given in Table II. Each compound was checked for carcinogenic, embryo toxin and teratogenic and 31 non-toxic compounds were chosen for molecular docking analysis.

Receptor model was exported and potential bindings sites were predicted in the Molegro Virtual Docker workspace as presented in the Table III with their coordinate position in the workspace. Missing coordinates of receptor was checked before loading. Amino acid residues around the binding cavity were given in the Table IV.

Molecular docking is a novel approach to study small compound inhibition to receptor protein. We docked 31 non toxic compounds with receptor model of $M$. tuberculosis arabinosyl transferase using Molegro Virtual Docker (MVD) software. MVD is molecular 
Table I

Physicochemical property of top ranking database compounds

\begin{tabular}{|lcccccc|}
\hline Compound ID & Formula & $\mathrm{HBA}$ & $\mathrm{HBD}$ & Rot B & MW & ClogP \\
\hline ZINC00388344 & $\mathrm{C}_{7} \mathrm{H}_{16} \mathrm{NO}$ & 1 & 1 & 1 & 130.1 & 0.8 \\
ZINC20441875 & $\mathrm{C}_{11} \mathrm{H}_{23} \mathrm{~N}_{2} \mathrm{O}$ & 1 & 3 & 4 & 199.2 & 0.6 \\
ZINC01690002 & $\mathrm{C}_{8} \mathrm{H}_{16} \mathrm{NO}$ & 1 & 1 & 4 & 142.1 & 0.6 \\
ZINC17316804 & $\mathrm{C}_{8} \mathrm{H}_{16} \mathrm{NO}$ & 1 & 1 & 4 & 142.1 & 0.6 \\
ZINC19889071 & $\mathrm{C}_{18} \mathrm{H}_{37} \mathrm{~N}_{3} \mathrm{O}$ & 2 & 1 & 4 & 311.3 & 1.0 \\
ZINC19889073 & $\mathrm{C}_{15} \mathrm{H}_{33} \mathrm{~N}_{3} \mathrm{O}$ & 2 & 1 & 5 & 271.3 & 0.0 \\
ZINC20441963 & $\mathrm{C}_{16} \mathrm{H}_{35} \mathrm{~N}_{3} \mathrm{O}$ & 0 & 1 & 7 & 269.3 & 3.0 \\
ZINCO1688588 & $\mathrm{C}_{8} \mathrm{H}_{18} \mathrm{NO}_{2}$ & 2 & 3 & 3 & 199.2 & 0.4 \\
ZINC19976556 & $\mathrm{C}_{10} \mathrm{H}_{21} \mathrm{~N}_{3} \mathrm{O}$ & 2 & 2 & 5 & 199.2 & 0.4 \\
ZINC37049708 & $\mathrm{C}_{12} \mathrm{H}_{29} \mathrm{~N}_{3} \mathrm{O}$ & 2 & 3 & 6 & 231.2 & -0.1 \\
ZINC37049709 & $\mathrm{C}_{12} \mathrm{H}_{29} \mathrm{~N}_{3} \mathrm{O}$ & 2 & 3 & 6 & 231.2 & -0.1 \\
Pubchem1793372 & $\mathrm{C}_{9} \mathrm{H}_{2} \mathrm{ON}_{2} \mathrm{O}_{3}$ & 3 & 3 & 10 & 204.1 & 1.0 \\
Pubchem18542010 & $\mathrm{C}_{9} \mathrm{H}_{16} \mathrm{O}_{5}$ & 5 & 2 & 9 & 204.1 & 0.21 \\
Pubchem21811791 & $\mathrm{C}_{10} \mathrm{H}_{20} \mathrm{O}_{4}$ & 4 & 2 & 10 & 204.1 & -0.0 \\
Chemspider8464931 & $\mathrm{C}_{12} \mathrm{H}_{16} \mathrm{~N}_{2} \mathrm{O}_{3} \mathrm{~S}$ & 4 & 3 & 7 & 268.1 & 0.6 \\
Chemspider8464933 & $\mathrm{C}_{12} \mathrm{H}_{16} \mathrm{~N}_{2} \mathrm{O}_{3} \mathrm{~S}$ & 4 & 3 & 7 & 268.1 & 0.6 \\
Chemspider16740754 & $\mathrm{C}_{11} \mathrm{H}_{19} \mathrm{~N}_{3}$ & 1 & 4 & 6 & 193.2 & 0.1 \\
ChemBank1036 & $\mathrm{C}_{20} \mathrm{H}_{28} \mathrm{~N}_{2} \mathrm{O}_{5}$ & 6 & 2 & 11 & 376.2 & 0.7 \\
ChemBank1176 & $\mathrm{C}_{10} \mathrm{H}_{24} \mathrm{~N}_{2} \mathrm{O}_{2}$ & 4 & 4 & 9 & 204.2 & 0.1 \\
ChemBank1608 & $\mathrm{C}_{21} \mathrm{H}_{31} \mathrm{~N}_{3} \mathrm{O}_{5}$ & 7 & 5 & 13 & 405.2 & -1.8 \\
ChemBank1000260 & $\mathrm{C}_{10} \mathrm{H}_{24} \mathrm{~N}_{2} \mathrm{O}_{2}$ & 4 & 4 & 9 & 204.2 & 0.1 \\
ChemBank1049255 & $\mathrm{C}_{14} \mathrm{H}_{28} \mathrm{~N}_{2} \mathrm{O}_{2}$ & 4 & 4 & 5 & 256.2 & 1.2 \\
\hline
\end{tabular}

Table II

\begin{tabular}{|c|c|c|c|c|c|c|}
\hline \multicolumn{7}{|c|}{ ADME of compounds } \\
\hline \multirow[t]{2}{*}{ Compounds } & \multicolumn{4}{|c|}{ Absorption } & \multicolumn{2}{|c|}{ Distribution } \\
\hline & HIA (\%) & $\begin{array}{l}\text { IVCEL } \\
(\mathrm{nm} / \mathrm{sec})\end{array}$ & $\begin{array}{c}\text { INVMCM } \\
\text { (nm/sec) }\end{array}$ & $\begin{array}{c}\text { IVSP } \\
\text { (logkp, cm/hour) }\end{array}$ & IVPPB (\%) & IVBBBP (\%) \\
\hline Chem2057082 & 92.5 & 53.8 & 77.5 & -2.5 & 62.11 & 0.2 \\
\hline Chemspider6763024 & 91.5 & 1.4 & 73.6 & -3.2 & 60.2 & 0.0 \\
\hline ZINC0568632 & 99.3 & 49.7 & 177.2 & -1.8 & 60.2 & 0.0 \\
\hline ZINC0038846 & 99.0 & 25.8 & 264.6 & -3.6 & 0.0 & 0.9 \\
\hline ZINC05105206 & 99.0 & 50.9 & 173.2 & -2.6 & 0.0 & 1.1 \\
\hline Pubchem1793372 & 78.8 & 21.3 & 8.4 & -3.5 & 30.2 & 0.1 \\
\hline ZINC17353697 & 87.4 & 37.9 & 227.9 & -4.9 & 7.4 & 0.4 \\
\hline Etha11 & 87.2 & 21.959 & 30.8 & 2.3 & 85.5 & 5.1 \\
\hline Etha17 & 70.7 & 0.410 & 1.7 & -5.0 & 0.0 & 0.5 \\
\hline ZINC00388344 & 99.039 & 25.8 & 264.6 & -3.0 & 0.0 & 0.9 \\
\hline Etha10 & 82.5 & 19.3 & 0.5 & -4.2 & 38.1 & 0.4 \\
\hline
\end{tabular}

visualization and molecular docking software which is based on a differential evolution algorithm; the solution of the algorithm takes into account the sum of the intermolecular interaction energy between the ligand and the protein and the intramolecular interaction energy of the ligand. The docking energy scoring function is based on the modified piecewise linear potential (PLP) with new hydrogen bonding and electrostatic terms included.

The ligands were optimized before docking for proper structural stabilization. We calculated stretch, bend, steth bend, torsion, non-1,4 VDW, 1,4 VDW, total energy (Kcal/mol) using MM2 module of Chembio office tool. Docking computation was done based on the parameters mentioned in the methodology. 


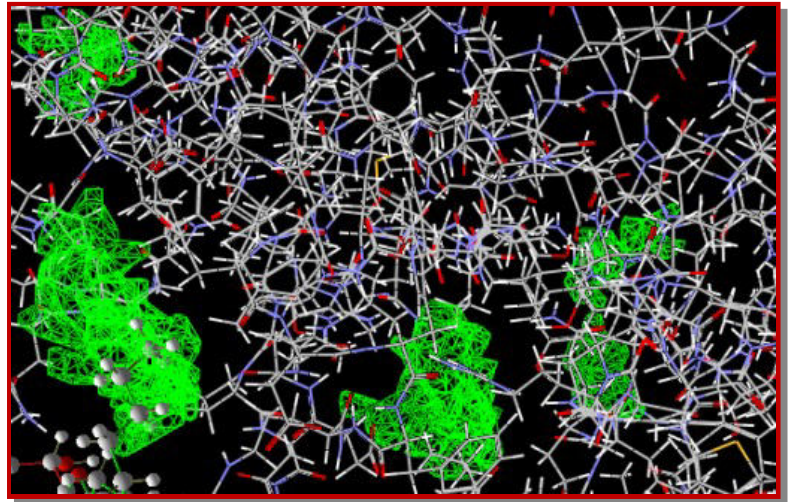

Figure 1: Predicted cavities of arabinosyl transferase

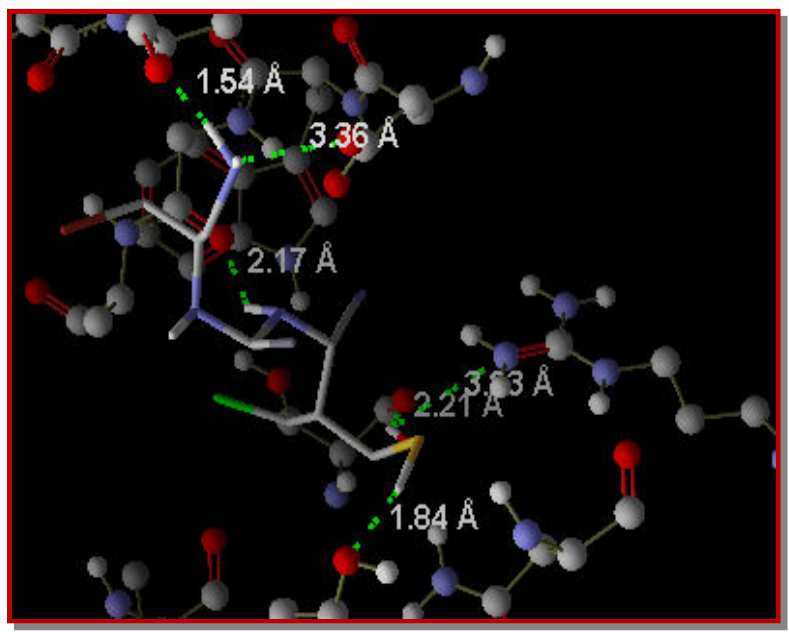

Figure 2: Receptor-ligand $\mathrm{H}$ bond interaction

While docking the receptor was set rigid and docked with the receptor binding site inside the constraint (Figure 1 and Figure 2) where, bond flexibility of lignds

\begin{tabular}{|c|c|c|c|c|c|}
\hline \multicolumn{6}{|c|}{ Table III } \\
\hline \multicolumn{6}{|c|}{ Predicted binding sites of the receptor } \\
\hline \multirow{2}{*}{ Cavity } & \multicolumn{3}{|c|}{ Position } & \multirow{2}{*}{$\begin{array}{l}\text { Volume } \\
\left(\AA^{3}\right)\end{array}$} & \multirow{2}{*}{$\begin{array}{c}\text { Surface } \\
\left(\AA^{2}\right)\end{array}$} \\
\hline & $\mathrm{X}$ & $\mathrm{Y}$ & $\mathrm{Z}$ & & \\
\hline 1 & 95.1 & -6.4 & 6.5 & 97.3 & 368.6 \\
\hline 2 & 90.3 & -18.4 & 1.2 & 74.2 & 240.6 \\
\hline 3 & 70.9 & -0.7 & 16.2 & 25.6 & 111.4 \\
\hline 4 & 70.9 & -0.7 & 16.2 & 20.0 & 84.5 \\
\hline
\end{tabular}

\section{Table IV}

Amino acid residues around the potential binding site

\begin{tabular}{|rrrr|}
\hline Ser739 & Asn740 & Leu743 & \multicolumn{1}{c|}{ Ala743 } \\
\hline Leu744 & Ala745 & Lys747 & Gly750 \\
Leu751 & Ala752 & Glu753 & Asp754 \\
Val755 & Leu756 & Lys1050 & Asp1051 \\
Asp1052 & Arg1055 & Trp1057 & \\
\hline
\end{tabular}

was set as "on". The docking result has predicted two database compounds and two analogues of ethambutol based on least energy score of rerank, moldock and $\mathrm{H}$ bond values as presen-ted in the Table V. Dock poses were further inspected for hydrogen bonding interaction with the receptor.

The compound Chemspider20572082 and Zinc00388344 showed highest rerank score of -117.9 and -107.3 with optimum hydrogen bonding with the receptor including two analogue of ethambutol as shown in the Table VI.

The compound Chemspider20572082 interacts with the amino acid residue Gly1058, Asp1052 and Asp1056 and forming three hydrogen bond interaction at the distance

\begin{tabular}{|c|c|c|c|c|c|c|}
\hline \multicolumn{7}{|c|}{ Table VI } \\
\hline \multicolumn{7}{|c|}{ Hydrogen bonding between ligands and receptor } \\
\hline & Ligands & Ligands & $\begin{array}{c}\text { Distance } \\
(\AA)\end{array}$ & Protein & Protein & Protein \\
\hline Ligand name & Atom name & Atom ID & $\begin{array}{c}\text { Distance } \\
(\AA)\end{array}$ & Atom Name & Atom ID & Amino Acid \\
\hline Etha 9 & $\mathrm{H}(1)$ & 17 & 3.25 & $\mathrm{O}(8)$ & 1934 & Val 1054 \\
\hline Etha 9 & $\mathrm{H}(1)$ & 17 & 2.54 & $\mathrm{~N}(7)$ & 1943 & Scr 1047 \\
\hline Etha 9 & $\mathrm{H}(1)$ & 17 & 2.24 & $\mathrm{O}(8)$ & 1948 & Scr 1047 \\
\hline Etha 9 & $\mathrm{H}(1)$ & 23 & 2.24 & $\mathrm{O}(8)$ & 2036 & Asp1056 \\
\hline Chem2057082 & $\mathrm{H}(1)$ & 25 & 2.43 & $\mathrm{O}(8)$ & 2055 & Gly1058 \\
\hline Chem2057082 & $\mathrm{H}(1)$ & 30 & 2.35 & $\mathrm{O}(8)$ & 1989 & Asp1052 \\
\hline Chem2057082 & $\mathrm{H}(1)$ & 26 & 1.99 & $\mathrm{O}(8)$ & 2036 & Asp1056 \\
\hline ZINCOO388344 & $\mathrm{H}(1)$ & 22 & 2.12 & $\mathrm{O}(8)$ & 1934 & Val1045 \\
\hline ZINCOO388344 & $\mathrm{H}(1)$ & 22 & 2.22 & $\mathrm{O}(8)$ & 2061 & Leu1060 \\
\hline ZINCOO388344 & $\mathrm{H}(1)$ & 22 & 2.26 & $\mathrm{O}(8)$ & 2064 & Leu1060 \\
\hline Ethambutol & $\mathrm{H}(1)$ & 20 & 2.03 & $\mathrm{O}(8)$ & 1948 & Ser1047 \\
\hline Ethambutol & $\mathrm{H}(1)$ & 29 & 2.32 & $\mathrm{O}(8)$ & 2055 & Gly1058 \\
\hline Ethambutol & $\mathrm{H}(1)$ & 29 & 3.01 & $\mathrm{O}(8)$ & 2036 & Asp1056 \\
\hline
\end{tabular}




\begin{tabular}{|c|c|c|c|}
\hline \multicolumn{4}{|c|}{ Table V } \\
\hline \multicolumn{4}{|c|}{ Docking result } \\
\hline Ligand & $\begin{array}{l}\text { MolDock } \\
\text { score }\end{array}$ & $\begin{array}{c}\text { Rerank } \\
\text { score }\end{array}$ & HBond \\
\hline $\begin{array}{l}\text { Chemspi- } \\
\text { der20572082 }\end{array}$ & -117.9 & -93.1 & -22.4 \\
\hline Zinc00388344 & -107.3 & -80.3 & -09.0 \\
\hline Etha9 & -104.1 & -76.7 & -05.5 \\
\hline Etha17 & -95.0 & -45.8 & -05.7 \\
\hline Etha10 & -61.5 & -44.8 & -04.2 \\
\hline Ethambutol & -55.6 & -40.0 & -12.4 \\
\hline
\end{tabular}

of 2.43, 2.35 and $1.99 \AA$ respectively. ZINCOO388344 is forming three hydrogen bonds with Val1045 and Leu1060 and clearly reflecting its novelty as a inhibitor of $M$. tuberculosis arabinosyl transferase in compared with ethambutol having poor reranking score of 39.980 .

Screening for alternative and effective drug is urgently needed to combat the drug resistance straings of $M$. tuburculosis (Burris, 2004; McIlleron et al., 2009; Zhang et al., 2014). The failure of ethambutol is another challenge. Therefore to meet the present challenges for inhibition of $M$. tuberculosis arabinosyl transferase by these compounds would be a useful starting point to design better therapeutics of $M$. tuberculosis and in vitro experiment on compounds, viz. Chem2057082 and ZINCOO388344 is recommended.

In this investigation, virtual screening has been performed using various filters. The screened compounds are subjected to molecular docking and result are analysis on the basic of rerank score and hydrogen bond interaction and it was found that 3 compounds showed better result out of 31 docked compound than the control drug. Further ADME and pharmacological effects of these compounds observed comparatively better bio-availability, distribution, absorption, drug likeness, and pharmacological effects than ethambutol. Hence, it could be concluded that these three compounds could be considered as potent drug candidate of M. tuberculosis.

\section{Acknowledgement}

The authors thankfully acknowledge the Department of
Biotechnology (DBT), Govt. of India for providing the Bioinformatics Infrastructure Facility (BIF) to CSIR-NEIST, Jorhat under the project "Creation of BIF for the promotion of biology teaching through bioinformatics, 2008".

\section{References}

Amin AG, Goude R, Shi L, Zhang J, Chatterjee D, Parish T. EmbA is an essential arabinosyltransferase in Mycobacterium tuberculosis. Microbiology 2008; 154: 240-48.

Burris HA. Dual kinase inhibition in the treatment of breast cancer: Initial experience with the EGFR/ErbB-2 inhibitor lapatinib. Oncologist 2004: 9(Suppl 3): 10-15.

Gogoi D, Bezbaruah RL, Bordoloi M, Sarmah R, Bora TC. Insights from the docking analysis of biologically active compounds from plant Litsea Genus as potential COX-2 inhibitors. Bioinformation 2012; 8: 812-15.

Harries AD, Dye C. Tuberculosis. Ann Trop Med Parasitol. 2006; 100: 415-31.

Jain A, Mondal R. Extensively drug-resistant tuberculosis: Current challenges and threats. FEMS Immunol Med Microbiol. 2008; 53: 145-50.

Kumar A, Sandramouli S, Verma L, Tewari HK, Khosla PK. Ocular ethambutol toxicity: Is it reversible? J Clin Neuroophthalmol. 1993; 13: 15-17.

Lagunin A, Stepanchikova A, Filimonov D, Poroikov V. PASS: Prediction of activity spectra for biologically active substances. Bioinformatics 2000; 16: 747-48.

Lopez AD, Mathers CD. Measuring the global burden of disease and epidemiological transitions: 2002-2030. Ann Trop Med Parasitol. 2006; 100: 481-99.

McIlleron H, Willemse M, Werely CJ, Hussey GD, Schaaf HS, Smith PJ, Donald PR. Isoniazid plasma concentrations in a cohort of South African children with tuberculosis: Implications for international pediatric dosing guidelines. Clin Infect Dis. 2009; 48: 1547-53.

Norinder U, Bergstrom CA. Prediction of ADMET properties. Chem Med Chem. 2006; 1: 920-37.

Thomsen R, Christensen MH. MolDock: A new technique for high-accuracy molecular docking. J Med Chem. 2006; 49: 3315-21.

Zhang Z, Wang Y, Pang Y, Kam KM. Ethambutol resistance as determined by broth dilution method correlates better than sequencing results with embB mutations in multidrugresistant Mycobacterium tuberculosis isolates. J Clin Microbiol. 2014; 52: 638-41. 